\title{
Indigenous ways of disaster preparedness in Zimbabwe: Lessons from living Heritage
}

\author{
Jacob Mapara \\ Chinhoyi University of Technology \\ Research Fellow - UNISA \\ jacob.mapara@gmail.com
}

\begin{abstract}
This paper argues that today's communities have suffered considerably due to severe droughts, floods and storms occurring in what can best be described as coming out of season. These have led to loss of lives, livestock and property. It asserts that some of these disasters are avoidable if communities learn from the intangible cultural heritage that guided the pre-colonials and those of the preindependence period when most Blacks still respected and appreciated their beliefs and value systems. It notes that while it is important to rely on the Meteorological Services Department for weather forecasting, events over the past few years have shown this Department's forecasts at times as unreliable. The paper therefore argues that Zimbabweans, especially those involved in crop and livestock production should also observe natural phenomena such as flora and fauna as was done by the people of old who got early warning signs from Mother Nature herself.
\end{abstract}

Key Words: indigenous knowledge systems, disaster preparedness, natural disasters, droughts, flooding, living heritage

\section{Introduction}

Qince time immemorial, humanity has always relied on technology to live comfortably. By technology here meant the use of tools and other implements that have today evolved to become machines. Technology also includes practices, traditions and activities that have sustained communities. Technology has therefore been part and parcel of humanity. When the people of old embarked on the use of technology, they also tapped into practices that were informed by years of experience and had been passed down inter-generationally as they traversed the continents. This knowledge was passed down usually in the form of practices and observations that are still employed today in some communities are known as intangible cultural heritage which is also called living heritage. 
The tragedy today is that most people have absorbed western knowledge and practices at the expense of those with indigenous roots. This has been detrimental as natural disasters like the 2004 Asian Tsunami and the effects of droughts and floods in Africa have shown that western technology and practices are not always reliable. Even some countries that reputedly have the best technology such as the United States of America have not escaped the wrath of 'Mother Nature' as was observed when Hurricane Katrina hit her shores (Driesen et al, 2005 p.6).

Additionally, some so-called modern technologies are detrimental to the environment when compared to their perceived backward cousin, local area technology that has been used and continues to be used at local levels and in a manner that is environmentally friendly. While this paper is not about modern technology and its negative effects on today's world, fact that going 'modern' and abandoning the tried and tested living heritage of the local communities has impacted negatively on today's communities in Zimbabwe as well as the formerly colonised in general is worth pointing out. Zimbabwe has lately become a victim of natural disasters like severe droughts and flooding in areas that in the past have recorded no such cases. Some of these disasters have befallen people who have abandoned their indigenous ways of preparing for natural disasters as regards droughts, hunger and flooding because they have concluded or been made to believe that the knowledge and ways of the past are archaic and not in sync with today's world.

\section{Areas of Research}

The research was carried out in Nyanga District of Manicaland Province, Eastern Zimbabwe, targeting Bende, Dazi, Matema, Nyadowa, Tangwena and Tombo I. With the exception of Chief Tangwena's area, the others are under Chief Saunyama. The areas relatively share the same climatic conditions being between 1800 and 2405 metres above sea level with Rukotso Mountain being the highest at an altitude of 2405 metres above sea level.

The inhabitants of these areas are largely communal farmers, with a few at Bende, Dazi and Matema venturing into small scale potato and apple production. As largely communal farmers, their agricultural activities are subsistence. It is significant pointing out that despite the onslaught of western education, which in the eyes of some in the country, and some agricultural 'experts' is considered the 'real' education, most of the farmers in these areas are still informed by their intangible cultural heritage (ICH) practices for their benefit. They continue to practice and transmit knowledge and practices that relate to disaster preparedness especially in the rainy season.

\section{Research Methods}

A qualitative approach, specifically the ethnographic methodology was used because of its appropriateness to case studies. Ethnography involves the study of communal interactions, behaviours, and perceptions that occur within communities, teams, 
organisations as well as clusters (Reeves, Kuper \& Hodges 2008 p.512). They further observe that ethnography provides rich, holistic insights into people's views and actions as well as the nature of the location they inhabit. Reeves et al (2008 p.337) further reveal the major features of ethnographic research as: a strong emphasis on exploring the nature of a particular social phenomenon, rather than setting out to test hypothesis about it, working best with 'unstructured data'. It investigates a small number of cases and the analysis of data involves the explicit interpretation of the meanings and functions of human actions; with the product of this analysis mainly taking the form of verbal descriptions and explanations. It was found appropriate because it goes beyond simple fact and surface appearances (Denzin 1989, 83).

This is so since it presents detail, context and emotion in addition to the webs of social relationships that bring people together. As a method, it establishes the importance of experience, or the sequence of events, especially for the person or persons in question. It focuses on the importance of for example, the experiences that the residents and farmers of the areas have gone through and how these experiences have sharpened their senses to respond and learn from the vagaries of weather. Qualitative research is particularly effective in the procurement of culturally specific information about the practices, values, opinions, behaviours and social contents of particular populations. It was therefore found to be relevant for this study because indigenous ways of forecasting on the weather are cultural heritage that is also steeped in the religious. In this research the writer was guided by the following four questions:

1. Munoona mamiriro ekunze mazuva ano aine chekuita here nekushomeka kwezvekudya? (Do you think the changes in climatic conditions today have an impact on food scarcity?)

2. Vachena vasati vauya, kana kuti chirungu chisati chapinda vanhu maiziva sei kuti mwaka unotevera unenge wakanaka kana kushata? (Before colonialism, or before western ways got the better of the people how did you tell whether the coming season was going to be a good one or a bad one?)

3. Ndedzipi nzira idzi? (What ways or methods did you use?)

4. Saka nzira idzi munoona dzichine zvadzinobatsira here mumazuva ano? (Do you think these methods or ways are still useful in this time and age?)

This research was carried out through informal interviews. The sample of the informants was purposefully done with two informants being identified per area, thus bringing the total number of informants to twelve (12). The average age of the informants was 55 years. The interviews were carried out at their homes or at popular drinking spots in their areas of residents. Informal interviews were opted for because the informants are more relaxed since they do not feel that someone is intruding into their lives.

Besides informal interviews, the researcher also used the observation method to confirm or disprove what he had got from his informants. Although he did not observe all the forms of weather forecasting that he was informed of he noted that the rain bird's cry 
was usually followed by rainfall. He also observed avian behaviour. Although unintended, the interviews ended up as focus group discussions that ended up as multifocal exchanges, which was good for the research. The discussions therefore had more input from others who buttressed and added more information to what the informant was giving. It really became a truly African situation where it is acknowledged that chako wega mukonde wesadza ${ }^{1}$. Everyone who was within range who believed they could contribute something did so.

\section{Justification of the study}

In an environment which is characterized by constantly changing weather patterns, this study is necessary. It is a call to indigenous people to go back to the basics and rely on a combination of the time-tested knowledge of their ancestors and that of western extraction. Ancestral knowledge has enabled most generations to sail through the harsh realities of weather's unpredictability.

The study realises that reliance on Eurocentric knowledge alone has left people more exposed than they were before this knowledge type was imposed on them. The study is also justifiable as a means to empower the African academic which unfortunately has largely been blinded by western ideas that have given the impression that Africa and the other formerly colonised were figuratively terra nullius in the academic sense. This misconception of the Euro-centricists is clearly amplified by Blaut (1993) in Battiste (n.d) who notes: "Eurocentric thought asserts that only Europeans can progress and that indigenous peoples are frozen in time, guided by knowledge systems that reinforce the past and do not look towards the future."

Battiste further argues that several stratagems have been used in the western academe to underpin the myth that regions outside Europe add nothing to the growth and expansion of knowledge in the humanities, arts, science, and technology. The writer further argues that in an effort to perpetuate such myths, western scholarship has downplayed and even ruled out the contributions of other peoples and civilisations to knowledge.

\section{Defining Disaster Preparedness}

These are mechanisms put in place by an organisation, community, state or nation as preventive measures to contain or mitigate the effects of a forecasted or anticipated disastrous event. The reasons for doing this are many, and they comprise attempts to minimise loss of life, reduce or minimise injury as well as damage to movable and immovable property. Disaster preparedness is also instituted to provide rescue, relief and rehabilitation services post-disaster. Being in a state of disaster preparedness additionally means that a community has the capacity and resources, both material and financial that

1 "What is really yours is a huge portion of sadza (pap)". This proverb really means that people cooperate for mutual benefit. 
will enable it to continue to sustain essential functions without being overwhelmed by the demand placed on them.

\section{Tapping into the Knowledge of the 'Ancients': Nature as Teacher}

The immediate bio-physical environment is a huge wall-less classroom. It is from it that the identified communities have learnt through their progenitors to observe nature. By learning and observing its secrets they have tapped into its lessons and survived gruesome hunger as well as other potentially life-threatening disasters such as floods. These people have benefitted from observing what is happening around them such that they have hardly gone wrong in their predictions of weather for a given agricultural season or at least for a given week in the minimum.

Since time immemorial, African indigenous communities have had well developed indigenous early warning disaster systems that were based not on equipment alone but also on observing nature. These were effective environmental management and coping strategies that enabled them to be more resilient to environmental change. The calamity is that this knowledge has become a casualty of the blitz of western educational systems that, partnered with the western version of Christianity, have denigrated indigenous knowledge as unscientific, relics of barbarism as well as remnants of heathenism.

In fact, western education has in the words of Odora-Hoppers $(2002, \mathrm{nd}):$ “. .. translated itself via the vivisectional mandate and socio-cognitive triage into a routinized project of erasure, epistemological silencing and cultural demise of the 'Other'..." These words are a significant pointer on how indigenous knowledge was shut out. The result of western education is that some indigenous people have ignored their heritage and essential ways of knowing that have sustained their progenitors for millennia. The good is that some sizeable numbers in the country have continued to practice what the 'ancients' have handed down to them as lessons for life. Most of these have never been disappointed when compared to some adherents of bookish knowledge and those who put their fate into the hands of machines only.

From the informants, trees have been observed to play an important role as weather forecasters for the forthcoming rainy season. Through the behaviour or blooming of trees in a certain way the people can tell whether the next season will be a good or bad one. The importance of trees is largely prevalent in areas such as Nyadowa, Tangwena's Tsatse area and some parts of Upper Tombo I where pfumvudza is an indicator of whether the rainy season will be a good one or not. Pfumvudza refers to the blooming of trees with new leaves after winter. This is when they put on new foliage.

This natural phenomenon is interpreted to inform people about the forthcoming rainy season. If the trees that bloom with new flowers and leaves are few and scattered, this is interpreted to mean that the rainy season is likely to be characterised by little and scattered rainfall, as is reflected in the number of trees that would have bloomed. These trees therefore function as a warning to those who may have surplus grain from the 
previous season not to dispose of it since the next season will most likely not be good and yields from most fields would probably be low.

According to all the respondents in the areas of Nyadowa, Tangwena and Tombo I, trees are significant indicators of the success or failure of a forthcoming season. One of the informants even stated that if trees that will be in bloom are scattered, and the mazhanje fruit are scattered as well even on one tree, it is not surprising to hear the elderly saying, "Nyamwaka tishapona ngemichero tsawana mushinda" (This season we are going to subsist on wild fruit like baboons). Some stated that they had learnt from their children that the world's climate was changing. To them this was not new. One of them, from Nyadowa indicated that schools were only beginning to confirm now what they had long observed that mvura haichanayi semanaire ayo yaiita kare (the rains no longer fall like they used to in the past). It is clear from these elders that they have gone through experiential learning and they have observed a lot over the years that from them one can learn only one thing: one ignores the lessons from nature and the past at his or her own peril.

Besides learning from flora, Nyadowa residents have also learnt from some birds such as storks (matsuramurove) and swallows (mhereperelnyenganyenga) whose presence are natural indicators of whether a rainy season will be a good one or not. Storks and swallows are both migratory birds that fly from the northern hemisphere to escape winter and fly to the warmer climes of the south in Asia and Central and Southern Africa. The Black stork (iconia nigra) is tropical but breeds in the north.

When in sub-Saharan Africa, like elsewhere, Black storks forage in wetlands. For this, the Manyika call them matsuramurowe (those that cause springs). If the matsuramurowe do not turn up in great numbers in a given summer, it is interpreted to mean that there will be little rainfall in the next season. If the birds are many, there will be a lot of rain that people should be careful not to cross flooded rivers. Areas in flood plains are also likely to be affected by flooding.

The researcher also gathered at Nyadowa that swallows help in forecasting weather. At the beginning of summer in Southern Africa, and in some parts of South Central Africa, usually around November-December, these birds come in from the north and leave the sub-region around April (Wakelin \& McKechnie 2009 pp.37-40). To the inhabitants of Nyadowa the appearance of these birds, portents a good forthcoming season. Albeit the birds' presence signals a good season, it also warns that the season may be affected by floods. While the presence of these birds (swallows and storks) at the beginning of summer to about March-April of the following year is a sign of an abundance of rains, their absence during, and especially at the beginning of the summer season is interpreted as an ominous sign of a poor rain season.

According to informants when the elders saw that there were no matsuramurowe and mherepere they concluded that the forthcoming season would be a disaster especially for crops because most of them are rain fed. This interpretation of natural phenomena to 
forecast on the immediate future is not something peculiar to these areas. Nakashima et al have also witnessed a similar trend in their study of the Americas, the Arctic/Polar Regions as well as small islands. What they have noticed in Tonga and Tuvalu is strikingly similar to what the Manyika have perceived as regards the flora and fauna of their area. They note:

Other key indicators are phenology (e.g. the abundance of particular fruit like mangoes and bread fruit is a sign of strong wind or heavy rain, and a rise in the ground water table of taro gardens is an indicator of rising seas); bird and animal behaviour (e.g. low flying albatross is a sign of poor weather, and animals seeking higher ground is a warning sign of approaching tsunami); and insects and arachnids (e.g. their appearance indicates the approach of unfavourable weather) (Tshuma \& Rurinda, 2012 p.93).

These observations are clear indicators that nature herself has a built-in mechanism to forecast weather behaviour which unfortunately has been ignored by most of today's people who seem to be of the opinion that being informed by indigenous knowledge systems is a sign of lack of reason, yet it is epistemologically correct to observe and learn from nature which has sustained humanity for millennia, long before the mono-vision of the so-called modern sciences and technology appeared on the radar of human civilisation.

The cry of certain birds also indicates imminent rain according to informants from Bende, Dazi, Matema and Tangwena. In these areas, especially those with forests and also in riverine but hilly and mountainous areas there is a bird with an onomatopoeic name called dzvotsvotsvo (the rain bird). This bird cries around mid-morning most of the times and its cry indicates that rains are imminent. The cry also warns those who would be outdoors to quickly look for shelter because in a short period of at most two hours after its cry, heavy rains at times accompanied by winds and lightning would fall. This bird's cry is significant because it does not only warn against getting wet but more importantly against floods and lightning. In a study that focuses on Chimanimani District in South Eastern Zimbabwe, Risiro, Mashoko, Tshuma and Rurinda (2012 p.564) found out that birds' behaviour in the area also indicates the imminence of the rainy season or its end

While the cry of the dzvotsvotsvo is an indicator of imminent rains, other birds, including domestic fowl are as well a source of weather forecasting. Some birds help people to forecast the weather for a minimum of at least two days and a maximum of about a week. One informant even claimed that one can forecast weather for a maximum of two weeks. The researcher was informed and also experienced it, that if birds did not go out of their nests when it was raining, it indicated that the rains would not last for the whole day; so they would wait and go out to forage for food. If on the contrary, the birds left their nests and fowls left their coops, it then means that the end of the rains is not imminent. The birds would have sensed that if they are to remain in their nests and coops they would die of hunger. 
When human beings observe such bird behaviour they would also learn that the rains would continue for at least that day. And if this continues on the following day, they may conclude that the rains would be with them for some time. Bird behaviour as weather forecast is very important because it warns people in the affected areas to gather firewood and to store it in dry places so that they would not have difficulties in keeping their fire alive and without smoke. The birds also warn people of potential hazards such as floods and of the dangers of crossing flooded rivers that may lead to unnecessary loss of life.

It was also brought out that when one is out in the open during the day and she or he observes birds rushing to their nests and home fowl getting into their coops or hiding in house verandas that is an indication of heavy rains coming and they will be accompanied by heavy storms. One of the informants added that for birds, they would be chirping loudly as they fly back to their nests. This behaviour is again a warning to human beings to get indoors or to look for shelter if they are far away from homes so that they get out of potential harm's way.

Mbito or mugohore (pied crow) is also a significant weather forecaster in the Bende, Dazi, Matema and Tangwena areas. This bird is visible usually early in the morning on river banks basking in the sun. Its appearance is an indication that winter has come. This appearance is a warning to people to gather firewood for heating their homes in the evenings because in the areas identified, temperatures are very low at night and winters are punctuated by drizzle.

Besides birds, frogs are also forecasters of a forthcoming season. At Nyadowa, information gathered indicated that so much frog croaking in rivers and streams indicates that the rains for the approaching season would be above average. As in the case of the birds like storks and swallows whose numbers tell whether the season will be good or not, if frogs do not croak a lot when summer is impending, the interpretation is that the season will be poor with below average yields. This low intensity croaking warns of forthcoming hunger. Acharya (2011 p.115) states that in traditional weather forecasting unusual animal behaviour that includes the unusual chirping and bathing with sand of birds as well as native frogs croaking near swampy areas indicates an oncoming and imminent rainy season. Although these observations relate to India and Asia, they echo what is also common in the areas under focus.

At Nyadowa and Tangwena it was observed that swarms of butterflies and locusts warn of a potentially poor harvest in the forthcoming season. Even if the rains are good, these pests usually spell doom to most subsistence farmers because even though some may have pesticides, most rural farmers do not have the capacity to buy pesticides in huge amounts, that is if ever they buy them in the first place. When they see the swarms of these pests in early summer usually when the seeds starting shooting, they conclude that that is a doomed season. They have stated that butterflies turn into makonye (worms) that eat the fledgling crops while locusts can wipe out whole fields overnight. The impact of locusts on crops has been known to be so devastating that a particular season has been 
called gore rehwiza/ndongwe (the year of the locusts). Unfortunately, no one knows which this year is or these years were.

Relying on flora and fauna for weather forecasting has been hailed as progressive in Kenya where modern weather forecasting methods have had little impact on rural communities. Here most of the inhabitants have little or no faith in people who forecast weather on the basis of some machines and not by observing nature. This has led the Intergovernmental Authority on Development (IGAD) Climate Prediction and Application Centre (IGAD/ICPAC) to partner rural communities so that they participate in the rehabilitation of 'shrines' of local flora and fauna that indigenous rainmakers rely on in weather forecasting (IGAD/ICPAC 2009 pp.1-2). The Kenyan scientists' realization that indigenous weather prediction knowledge is significant is a milestone worth applauding.

In these areas of Nyanga, between August and September children catch humbwi (edible black crickets) in dambos/tambwes ${ }^{2}$. Humbwi's availability in high numbers indicate not only the nearness of the summer season, but also the fact that the rains would be good. The inverse is true if humbwi are few. Other edible insects whose presence is interpreted to mean the proximity of the rainy season are nyenze (cicadas). Risiro et al (2012 p.563) also make reference to the cicadas and their chirping as indicators of forthcoming rains in Chimanimani, Zimbabwe.

Although flora and fauna have a huge influence on weather forecasting and therefore disaster preparedness in the areas under study, it merits pointing out that the respondents also mentioned other natural phenomena that foretell the weather. The informants as well revealed observing wind direction as informative on the forthcoming season. They stated that when summer is approaching, and the prevailing wind is the easterly or south easterly, the forecast is that the season is likely to have low rains since this wind called petagomwe (pack your bag) is not associated with rain bearing clouds but with wind and in some instances, mist. The nomenclature petagomwe itself is very revealing. It means that inhabitants of the areas affected by this wind persistently should prepare to pack their bags so that when the season completely fails they should carry their bags to go and buy, barter or beg for grain to feed their families. The same winds also function as a warning to some people who would still be having grain not to dispose of it because they will with their relatives and neighbours need it in their hour of greatest need. If they sell, the season may prove to be a real disaster to their families.

The contrary is equally true of northerly or north westerly winds (mhepo yembambara). If these winds prevail at the onset of summer and remain so throughout, they are bearers of a good rainy season and health harvests. The forthcoming season will be one of plenty. These rains which are in the inter-tropical convergence zone is usually heavy and

${ }^{2}$ These are shallow wetlands in central, southern and eastern Africa, predominantly in Zambia and Zimbabwe. 
can cause flooding. Because of their heaviness and being highly predictable, the Shona acknowledge their heavy downpours through the proverb, kutiza mvura yembambara, tiza ichabva kure (to avoid getting soaked by the northerly rains, make haste while they are still far). The wind's direction is a warning to travellers that they should also not cross flooded rivers.

It is as well not advisable to cross rivers in summer even if the river's waters appear to be clear and calm on the surface. Residents of Dazi and Tangwena areas pointed out that upstream, rivers like Samba (Kaerezi), may appear clear and quiet on the surface when below they have very strong currents. According to informants before one decides to cross the river, she/he has to carefully scan the water's surface where some particles like a few leaves, or even some insects would be floating. They pointed out that these are indications that the waters are very high. Another indicator is the audible one. The researcher was informed that when one hears rivers that are normally quiet making a lot of sounds; that is an indication that they have had their fair share of water and run-off water.

All informants stated that the moon is a significant indicator of the forthcoming rainy season. They declared that if there is a halo on the moon (dziva pamwedzi) as the year progresses towards the rainy season that indicates a good impending season. Risiro et al (2012 pp.564-5) make a similar observation that however, focuses on moon shapes and phases throughout the year. While they refer to the different seasons and shades of brightness of the moon at different times of the year as well as the month, they in addition mention the appearance of the halo on the moon that is itself a significant indicator of the onset of the rainy season.

\section{Mitigating hunger}

Flora and fauna in addition to the terrestrial bodies inform the inhabitants of the areas under study, about the rains or their potential for not falling in adequate amounts in a given season. It is not all about rains and floods but also droughts and near drought situations. In such conditions, residents take mitigatory measures to prepare for a rainy day. Because these people know that not all seasons will be good, they had a zunde ramambo (the king's field). The zunde was a communal field in each dunhu (ward) and the sadunhu (chief or sub-chief) was the local area custodian of the grain that was kept in a special granary. The chief was not expected to use the harvest for his benefit because the produce belonged to the community. The harvest was only to be used in times of need and again not everyone got this assistance but largely the vulnerable especially the very old ones who had no children to look after them.

The zunde ramambo practice has almost died although the Government of Zimbabwe through the Nutrition Unit of the Ministry of Health and Child Welfare has attempted to have this re-introduced (Mararike, 2001 p.53). Mararike further notes that attempts to revive this practice, have met with limited success because some chiefs and their 
communities have not even discussed it, while in others like Samambwa's, Kwekwe have implemented it (Mararike, 2001, 54). Although Mararike states that attempts at reviving zunde have had little success, this researcher found out that the main reason for it was food security, not nutrition. Among the Tangwena people the zunde practice was still prevalent in the 1970s when they were fighting eviction from their lands by the Smith regime.

Even when most Tangwenas left the country and became refugees in neighbouring Mozambique, they continued with the practice to ensure food security. They had a communal field they called Kumazhanje (At the Wild Loquats). While the name was a disguise against the Rhodesian forces, the field ensured that the Tangwenas had food since there was very little chance for them to attend to their fields in Zimbabwe because of the Rhodesian forces' continuous disruptions.

Besides mitigating drought through zunde ramambo, the inhabitants of these areas have their own silos that are anchored by stone pillars. This is because these areas are all in agro-ecological region 1 which has high rainfall. These stone pillars leave room for runoff water to pass under the granaries (tsapi/matura) thus protecting the harvest from moisture that may ruin the whole harvest. In some areas, such as Bende and Tangwena, the inside of the granary is lined with cow-dung which acts as a grain borer repellent. They also place the nyakambanje plant in the granary as an additional repellent.

With crops' maturity people's fears shift from those of poor or incessant rains to fires. In all the areas, especially Bende and Tangwena, when crops mature and harvest time beckons, people catch magodo (edible flying insects) using fire to smoke them to immobility. The magodo catchers thus have to do this especially in the evening when moisture sets in. They also have to go in groups to help control the fire which if it gets out of control may burn down people's homes, fields and granaries.

Indigenous knowledge systems are broad and varied that they defy categorisation. They are not a science in the sense 'science' is used and understood. Neither are they a philosophy because they as well have a spiritual dimension to them. This spiritual aspect of IKSs has been tapped into for purposes of protecting crops. At Nyadowa, people are advised against calling baboons by their proper nomenclature wanamutiro/wamutiro/matiro but to use the honorific Samasango (The Owner of the Forests/ Those who stay in the forests).

The belief is that to call them by their real name is disrespect for the ancestors of the land which will result in crop destruction by these and other animals. In the Tangwena area all people irrespective of religious affiliation contribute in kind and labour in the brewing of beer offered to the local spirit medium. The inhabitants stoutly believe that this ritual helps to ward off pests and minimizes disaster. Nakashima et al (2012 p.30) also highlight the significance of religion in disaster preparedness and management by observing that indigenous knowledge encompasses more than empirical understandings and deductive thoughts, but in addition to these, there is also community know-how, 
practices and technology; social organisation and institutions as well as spirituality, rituals, rites and worldview. In short, the reliance on religion besides observing nature is an indication that IKSs are a holistic type of science. They are a practical type of framework or model that allows people to function and survive in their own immediate environment.

Some wetlands have cultivable spaces called matoro. For instance, just after Troutbeck, is a place that is called Nyatoro, a toponym derived from matoro which is low lying, well watered and fertile. In summer, such places can be affected by a lot of rain but between August and September the inhabitants of the area make ridges where they plant maize and taro (madhumbe). Ridging ensures good drainage. The researcher was informed that if ridging was not done the crops would not thrive because of water logging. It is interesting to note that cultivating on wetlands was also practiced in the Matopo Hills area before colonialism. Although Ranger does not mention ridge construction, he states that each August pumpkins, green mealies, vegetables and rice were planted $(1999,24)$. August is also the month when the Tangwena, Nyadowa and Tombo I inhabitants embark on wetlands' cultivation.

Terracing of slopes is still very much alive. It was prevalent in pre-colonial Zimbabwe and gradually died down as when whites labelled the practice backward. Interestingly, one person who was a village head at Nyadowa, Matongowa Bridge Guta was allowed to continue with the practice by the Land Development Officers (LDOs) (madhumeni). When he stopped cultivating the slopes that he called matema, new trees recolonised the area. This however, was not for long because one teacher at Mutetwa Primary School Guta's nephew, Lovemore Hamunakwadi has revived the practice.

While Hamunakwadi is the only practitioner of slope agriculture at Nyadowa, this practice is prevalent at Matema and Tombo I. Like at Nyadowa, the Tombo I and Matema agriculturalists call the terraces chinjiri, a name derived from an ideophone that means to lie across. The purpose of building chinjiri is not only to create space to cultivate in hilly and rocky areas but to in addition minimise soil erosion. It is also clear that in an area like Nyanga where rainfall is generally above average, chinjiri help to ensure that the area is not prone to landslides. Today even though the climate is becoming less predictable, terracing is still important because at times rains are heavier than they usually are.

When the people of Nyadowa expect low rainfall, they implement kupandira (dry planting). Through practicing kupandira it is hoped that the seed that is planted in this manner will germinate with the first rains. The practice of kupandira is an indication that the people of Nyadowa and by extension those of old knew that seasons are inconsistent and because of that they needed to take steps that would ensure that they would at least have some harvest. 


\section{Conclusion}

This paper has argued on the importance of indigenous practices that relate to disaster preparedness and mitigation strategies. It has shown that this living heritage has empowered communities that still practice it to forecast the weather of the forthcoming season and have made plans that would ensure that their food reserves are secure if the weather shows signs of ushering in a poor season. The paper has further posited that through deciphering natural signs these communities have succeeded in avoiding catastrophes like being swept away by flooded rivers. The paper therefore concludes that it is important for today's people to learn from the knowledge that was handed down, not only in the areas studied but in all areas of the country as well as all former colonised people because they have a wealth of knowledge that may benefit today's people. The idea is not to treat each knowledge form as a separate entity or to perceive the knowledge forms of the formerly colonised as backward but to take all of them as a celebration of cultural diversity and an acceptance of the complementarity of knowledge thus making humanity richer and more knowledgeable. The Shona proverb ndarama yakawanikwa paigara gudo (gold was discovered at what the abode of baboons was once) emphasizes the knowledge and benefits that accrue to humanity relating to indigenous weather forecasting and disaster preparedness.

\section{References}

Acharya, S. (2011). Presage Biology: Lessons from nature in weather forecasting. In Indian Journal of Traditional Knowledge, 10(1), pp.114-124.

Battiste, M. (2013). Indigenous Knowledge: Foundations for First Nations, Retrieved from http://www.win-hec.org/docs/pdfs/Journal/Marie\%20Battiste\%20copy.pdf Accessed on 29 April 2013.
BusinessDirectory.com Disaster Preparedness Retrieved from http://www.businessdictionary.com/definition/disaster-preparedness.html Accessed on April 2013.

Denzin, N. (1989). Interpretive Interactionism. London: Sage.

IGAD/ICPAC. (2009). Stories from the field: Linking traditional and modern forecasting in Western Kenya. Retrieved from http://www.idrc.ca/EN/Programs/Agriculture and the Environment/Climate C hange and Adaptation in Africa/Documents/Forecasting-in-western-Kenya.pdf Accessed on 24 April 2013.

Driesen, D. M. et al. (2005). An Unnatural Disaster: The Aftermath of Hurricane Katrina. Washington: Center for Progressive Reform. 
Mararike, C. (2001). Revival of Indigenous Food Security Strategies at the Village Level: The Human Factor Implications. In Zambezia: Journal of Humanities, XXVIII(i): pp.53-65.

Nakashima, D., McLean, K.G., Thulstrup, H., Castillo, A.R. \& Rubis J. (2012). Weathering Uncertainty: Traditional Knowledge for Climate Change Assessment and Adaptation. Paris and Darwin: UNESCO and United Nations University.

Odora-Hoppers, C. (2002). Recognizing, Promoting, Protecting and Integrating IKS into the Mainstream: Critical Concerns and Challenges at Policy and Institutional Levels in South Africa. Paper presented at the Linking Traditional and Scientific Knowledge for Sustainable Development, World Summit on Sustainable Development, 29 August 2009. Ubuntu Village, Johannesburg.

Ranger, T.O. (1999). Voices from the Rocks: Nature, Culture, and History in the Matopos Hills of Zimbabwe. Bloomington: Indiana University Press.

Reeves, S., Kuper, A. \& Hodges, B.D. (2008). Qualitative research methodologies: ethnography. British Medical Journal. 337: a1020. DOI:10.1136/bmj.a1020 http://www.bmj.com/archive/Accessed 21 April 2013.

Risiro, J., Mashoko, D., Tshuma, D. \& Rurinda, E. ( 2012). Weather Forecasting and Indigenous Knowledge Systems in Chimanimani District of Manicaland, Zimbabwe in Journal of Emerging Trends in Educational Research and Policy Studies (JETERAPS), 3(4) pp. 561-566.

Wakelin, J. \& McKechnie, A. (2009). Tracking Blue Swallow Migration patterns: Connecting the Dots. In Africa - Birds and Birding 14(5) p. 36-40. 